\title{
AVALIAÇÃO DA RELAÇÃO DA TEMPERATURA DE MOSTURAÇÃO NA FORMAÇÃO DE DIFERENTES TIPOS DE AÇÚCARES NO MOSTO CERVEJEIRO
}

\author{
D. TOSS $^{1}$, A. A. CRISTOFOLI ${ }^{1}$ \\ ${ }^{1}$ Universidade de Caxias do Sul, Centro de Ciências Exatas e Tecnologia \\ E-mail para contato: dtoss@ucs.br
}

\begin{abstract}
RESUMO - A cerveja é uma das bebidas mais consumidas do mundo, sendo sua qualidade dependente das etapas de produção como a mosturação, onde resultam as transformações do amido em açúcares, pela ação de enzimas. Desta forma, foram realizados estudos relacionando a temperatura da mosturação, com a formação dos diferentes açúcares no mosto. Malte do tipo pilsen foi utilizado para a mosturação em 4 diferentes temperaturas, 62, 64, 66 e $68^{\circ} \mathrm{C}$. Transcorridos 90 min de mosturação, as amostras foram analisadas pela cromatografia líquida de alta eficiência (CLAE). Os resultados experimentais mostraram que a temperatura de mosturação influenciou na formação dos açúcares do mosto. Nas temperaturas mais baixas analisadas, a mosturação tende a produzir açúcares de cadeia curta como glicose, frutose e maltose, evidenciando a ação das enzimas do tipo $\beta$-amilase. Já nas temperaturas mais elevadas, com a ação da enzima $\alpha$-amilase, prioriza-se a formação dos açúcares de cadeia mais longa como as dextrinas.
\end{abstract}

\section{INTRODUÇÃO}

A cerveja é, sem dúvida, a bebida alcoólica mais difundida no mundo e seu sucesso está relacionado, entre outros fatores, a sua aptidão para a produção em larga escala (Grassi et al., 2014a). Além de outros componentes a cerveja tem em sua composição 3,3 a 3,4\% de carboidratos, sendo a maioria dextrinas (75-80\%), seguido dos monossacarídeos e oligossacarídeos (20-30\%) e, ainda, 58\% de pentosanas (Arfelli e Sartini, 2014). Estes carboidratos são resultado da inatividade das leveduras de fermentação sobre açúcares de cadeias longas, como as dextrinas, que podem estar presentes no mosto fermentativo em até $20 \%$ do total de açúcares. Como as dextrinas são açúcares não-fermentáveis, forma-se, então, o açúcar residual encontrado na cerveja (Grassi et al., 2014b). Dependendo do estilo de cerveja que se deseja produzir deve-se obter um mosto fermentativo com maior ou menor teor de dextrinas. A temperatura atuadiretamente na concentração destes açúcares, agindo na atividade enzimática, sendo assim, um controle na programação da temperatura de mosturação é crucial sobre a qualidade da bebida, além de assegurar a atividade enzimática do meio (Gebremariam et al., 2013).

Como citado, a temperatura de mosturação é fator importante para a determinação do tipo de cerveja que se deseja produzir. Na mosturação observa-se a ação de enzimas que têm a capacidade de 
converter o amido do cereal em açúcares. A temperatura de trabalho afeta diretamente a atividade das enzimas $\alpha$-amilase e $\beta$-amilase. A $\alpha$-amilase tem sua atividade acentuada em temperaturas mais elevadas, desta forma espera-se obter um mosto fermentativo mais rico em dextrinas (açúcares de cadeia longa). Por outro lado, em temperaturas mais brandas, a atividade da $\beta$-amilase se sobressai, formando açúcares de cadeia curta como a glicose, a frutose e a maltose (Lamsal et al., 2011).

A cevada é o cereal mais importante para a produção de cerveja, sendo amplamente utilizado, por apresentarelevado teor enzimático, embora outros cereais podem também serem empregados como matéria-prima. O processo de maltagem, consiste na produção e ativação das enzimas (Silva et al., 2008). As enzimas, por sua vez, atuarão no processo de maceração, que consiste na conversão do amido em açúcares. A enzima $\alpha$-amilase hidrolisa as ligações $\alpha$-1,4-glicosídicas das moléculas de amido, liberando oligossacarídeos de 6-7 unidades de glicose. Já a $\beta$-amilase realiza o mesmo processo de hidrólise, porém libera oligossacarídeos de cadeias menores, como a maltose (duas moléculas de glicose) (Pomilio et al., 2010).

Desta forma, o objetivo do trabalho foi estudar a composição dos açúcares presentes no mosto fermentativo, elaborado a partir de malte tipo pilsenem diferentes temperaturas de mosturação. Foram preparadas diferentes amostras, em diferentes temperaturas, e avaliado o perfil de açúcares através da cromatografia líquida de alta eficiência.

\section{MATERIAIS E MÉTODOS}

\subsection{Materiais}

O malte selecionado para a obtenção das amostras é o tipo pilsen(R.W. Emmel). O malte pilsenfoi selecionado por ser o mais utilizado e por possuir alta capacidade de conversão de amidos. A água utilizada na mosturação foi a água Milli-Q, obtida do equipamento Millipore Corporation. Seu emprego foi devido às análises realizadas por cromatografia líquida de alta eficiência, que requer isenção de íons.

\subsection{Preparação das amostras}

O malte foi moído utilizando-se um moinho de rolos o qual permite expor o endosperma, preservando a casca. Na sequência, a água foi aquecida a $55^{\circ} \mathrm{C}$ e adicionado o malte moído numa relação de 3L de água para cada $\mathrm{kg}$ de malte. $\mathrm{O}$ sistema permaneceu sob agitação constante. Com a adição do malte a temperatura do meio reduziu para $51^{\circ} \mathrm{C}$. A partir deste ponto, percorreu-se a mosturação com a elevação da temperatura para 4 diferentes patamares a uma taxa de $1{ }^{\circ} \mathrm{C} / \mathrm{min}$. Isso resultou em 4 diferentes amostras, com temperatura de mosturação variando de 62 a $68^{\circ} \mathrm{C}$, como mostra a Tabela 1. Outros parâmetros foram mantidos constantes, como $\mathrm{pH}$ do meio $(5,3)$ e tempo de mosturação (90 min). 
Tabela 1 - Condiçõesexperimentais

\begin{tabular}{|c|c|}
\hline Amostra & Temperatura de mosturação $\left({ }^{\circ} \mathrm{C}\right)$ \\
\hline A1 & 62 \\
\hline A2 & 64 \\
\hline A3 & 66 \\
\hline A4 & 68 \\
\hline
\end{tabular}

Após a mosturação, as amostras foram filtradas, utilizando-se um filtro específico para cerveja com malha de abertura de $1 \mathrm{~mm}$.Sobre o meio filtrante fez-se a formação de uma torta de filtração pela passagem consecutiva das amostras. Esse procedimento resultou em um fluido isento de partículas, porém turvo, que foi acondicionadas em frasco âmbar e mantidos refrigerados a $0^{\circ} \mathrm{C}$.

Após a mosturação, as amostras foram filtradas, utilizando-se um filtro específico para cerveja com malha de abertura de $1 \mathrm{~mm}$ (Figura 1-a). Sobre o meio filtrante fez-se a formação de uma torta de filtração pela passagem consecutiva das amostras (Figura 1-b). Esse procedimento resultou em um fluido isento de partículas, porém turvo, que foi acondicionadas em frasco âmbar e mantidos refrigerados a $0^{\circ} \mathrm{C}$.

\subsection{Análise dos açúcares totais}

A análise dos açúcares totais foi realizada pelo método de Felling (Oreglia, 1979). Para as análises foram feitas diluições das amostras, com água destilada, numa relação de 10:1. Foi preparada uma solução titulante composta por $5 \mathrm{ml}$ de Felling A, $5 \mathrm{ml}$ de Felling B, 50ml de água destilada, a qual foi aquecida até a ebulição. As amostras de mosto diluídas foram tituladas, utilizando indicador azul de metileno. $\mathrm{O}$ ponto de viragem foi observado no momento em que a solução de Felling atinge a coloração laranja. A concentração de açúcares totais nas amostras foi obtida segundo a Equação 1, onde $\mathrm{C}$ é a concentração de açúcares totais (expressa em $\mathrm{g}$ de açúcar/L de mosto), $f_{F}$ é o fator do Felling, $f_{D}$ é o fator de diluição das amostras e $\mathrm{V}$ é o volume $(\mathrm{em} \mathrm{mL})$ gasto na titulação.

$C=\frac{f_{F}}{V} f_{D}$

\subsection{Análise decromatrografia líquida de alta eficiência (CLAE)}

As amostras foram analisadas em triplicata, num equipamento de cromatografia líquida de alta eficiência (CLAE) da marca HP modelo 1100, coluna Amilex HPX-87H equipado com detector UV a 
350nm e sistema quaternário de bombas. Ácido sulfúrico com concentração 0,004M foi utilizado para a fase móvel. O volume de amostra injetado foi de $50 \mu \mathrm{L}$. O tempo de cada análise foi de $60 \mathrm{~min}$, a temperatura foi mantida a $60^{\circ} \mathrm{C}$ e a vazão da parte móvel foi mantida a $0,6 \mathrm{~mL} / \mathrm{min}$, de acordo com Sluiter et al. (2008), com algumas modificações. Como padrões para análise foram utilizados a maltose, glicose e dextrinas, ambos da Sigma-Aldrich.Para a quantificação dos açúcares, foi necessária o levantamento da curva de calibração para cada composto. Diferentes concentrações de compostos padrão, foram analisadas, relacionando-se a concentração do composto com a área obtida do cromatrograma. A curva de calibração permitiu expressar a quantidade de açúcar em g/L de mosto.

\section{RESULTADOS E DISCUSSÃO}

As análises em cromatografia líquida de alta eficiência, utilizando os compostos padrão, permitiram identificar o tempo de retenção para a maltose, a glicose e as dextrinas, nos tempos de $7,77,8,25$ e 6,41 min, respectivamente. Para cada composto foi elaborada a curva de calibração, como mostram as Equações 2 a 4.

$$
\begin{aligned}
& \text { Área }=3,3 \cdot 10^{5} \mathrm{C}_{M}-2,0 \cdot 10^{6}\left(R^{2}=0,998\right) \\
& \text { Área }=3,2 \cdot 10^{5} \mathrm{C}_{G}-4,9 \cdot 10^{4} \quad\left(R^{2}=0,999\right) \\
& \text { Área }=2,3 \cdot 10^{5} \mathrm{C}_{D}-3,1 \cdot 10^{5} \quad\left(R^{2}=0,997\right)
\end{aligned}
$$

Onde:

$$
\begin{aligned}
& \text { Área = área do pico do cromatograma; } \\
& C_{M}=\text { concentração de maltose }(\mathrm{g} / \mathrm{L}) ; \\
& \mathrm{C}_{\mathrm{G}}=\text { concentração de glicose }(\mathrm{g} / \mathrm{L}) ; \\
& \mathrm{C}_{\mathrm{D}}=\text { concentração de dextrinas }(\mathrm{g} / \mathrm{L})
\end{aligned}
$$

A Figura 1 mostra os cromatogramas, com os açúcares identificados, para as diferentes amostras. Observa-se que todos os 3 açúcares estão presentes nas amostras e, a partir das curvas de calibração, foi possível quantifica-los. A Tabela 2 mostra a concentração de maltose, glicose e dextrinas, bem como a concentração de açúcares totais. 

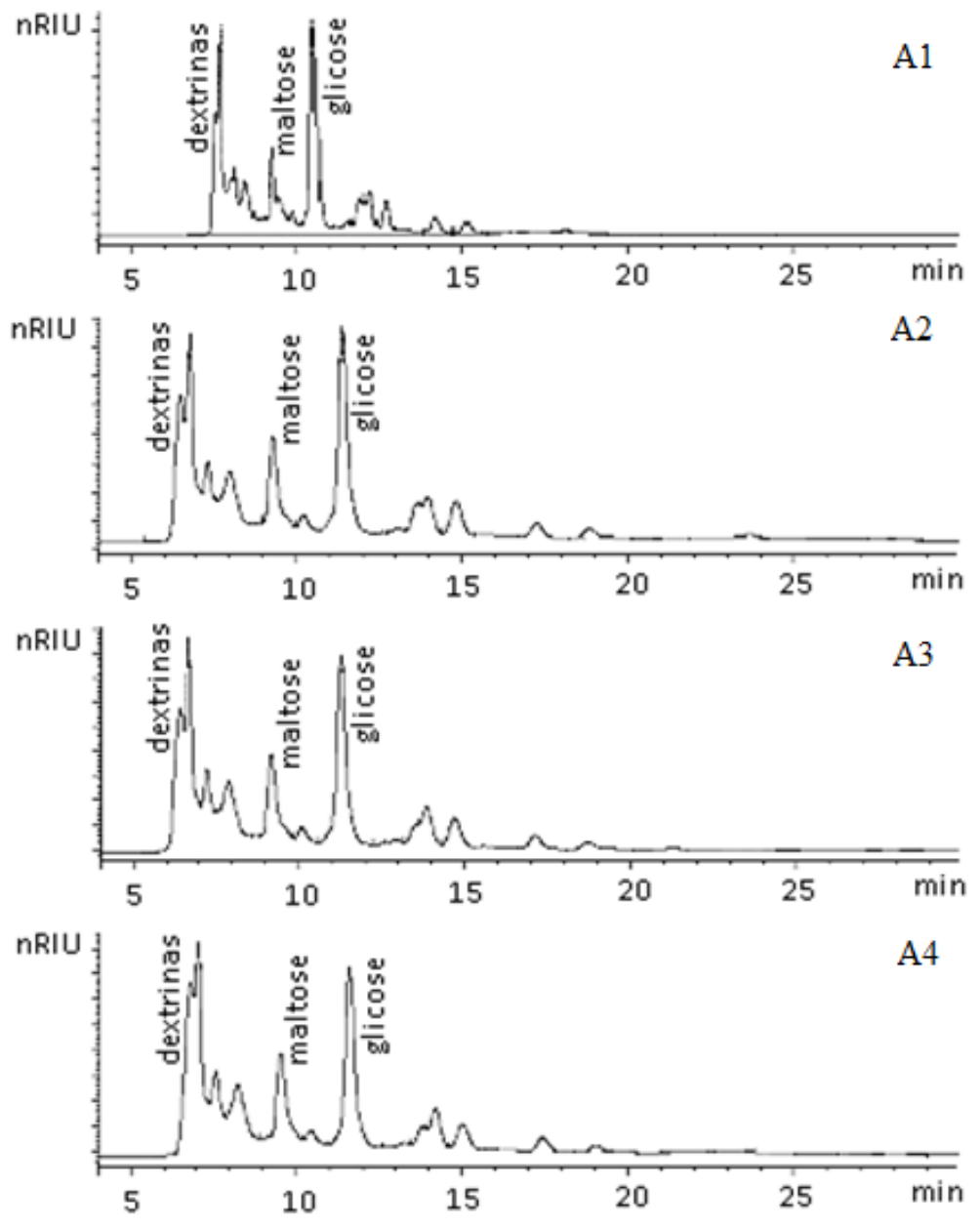

Figura 1 - Cromatograma das amostras de mosto.

Ao analisar a Tabela 2, observa-se que a concentração de glicose tende a cair com o aumento da temperatura, sendo a $\beta$-amilase agindo nas temperaturas de 62 e $64^{\circ} \mathrm{C}$. Por outro lado a concentração de maltose aumenta com a temperatura, tendo máxima concentração na temperatura de $66^{\circ} \mathrm{C}$. No caso das dextrinas o aumento da concentração é mais evidente na variação de temperatura de $66^{\circ} \mathrm{C}$ para $68^{\circ} \mathrm{C}$, sendo sua concentração aumentada em $23,7 \%$. Isso evidencia a maior atividade da enzima $\alpha$ amilase nas temperaturas de 66 e $68^{\circ} \mathrm{C}$. Os açúcares totais tiveram pouca variação na concentração nas diferentes amostras. 
Tabela 2 - Concentração de açúcares nas diferentes amostras.

\begin{tabular}{|c|c|c|c|c|c|c|}
\hline Amostra & $\begin{array}{c}\text { Temperatura } \\
\text { de mosturação } \\
\left(\mathbf{C}^{\circ} \mathbf{C}\right)\end{array}$ & $\begin{array}{c}\text { Concentração } \\
\text { de maltose } \\
(\mathbf{g} / \mathbf{L})\end{array}$ & $\begin{array}{c}\text { Concentração } \\
\text { de glicose } \\
(\mathbf{g} / \mathbf{L})\end{array}$ & $\begin{array}{c}\text { Concentração } \\
\text { de dextrinas } \\
(\mathbf{g} / \mathbf{L})\end{array}$ & $\begin{array}{c}\text { Açúcare } \\
\mathbf{s} \text { totais } \\
(\mathbf{g} / \mathbf{L})\end{array}$ & $\begin{array}{c}\text { Açúcares não } \\
\text { identificados } \\
(\mathbf{g} / \mathbf{L})\end{array}$ \\
\hline A1 & 62 & 74,95 & 26,26 & 48,86 & 186,57 & 36,50 \\
\hline A2 & 64 & 77,63 & 19,06 & 51,51 & 190,21 & 42,02 \\
\hline A3 & 66 & 86,79 & 15,77 & 53,30 & 183,11 & 27,24 \\
\hline A4 & 68 & 83,47 & 15,45 & 65,96 & 186,73 & 21,85 \\
\hline
\end{tabular}

Nota: ${ }^{1}$ Os açúcares não identificados foram calculados pela diferença entre os açúcares totais e a soma das concentração dos açúcares identificados em CLAE.

Com o objetivo de melhor visualizar o efeito da temperatura sobre a atividade das enzimas, construiu-se o gráfico da Figura 3. A fonte de carboidratos que deram origem aos diferentes açúcares é o amido, composto por cadeias longas de glicose, que é praticamente constante em todas as amostras. A quebra destas cadeias faz surgir a glicose, a maltose e as dextrinas. $\mathrm{Na}$ mais baixa temperatura estudada, a concentração da molécula única de glicose é a maior. Com a elevação da temperatura $\left(64\right.$ e $\left.66^{\circ} \mathrm{C}\right)$, a glicose dá espaço para cadeias maiores como a maltose(duas moléculas de glicose), que, por sua vez, cede lugar às dextrinas (diversas moléculas de glicose) na temperatura de $68^{\circ} \mathrm{C}$.

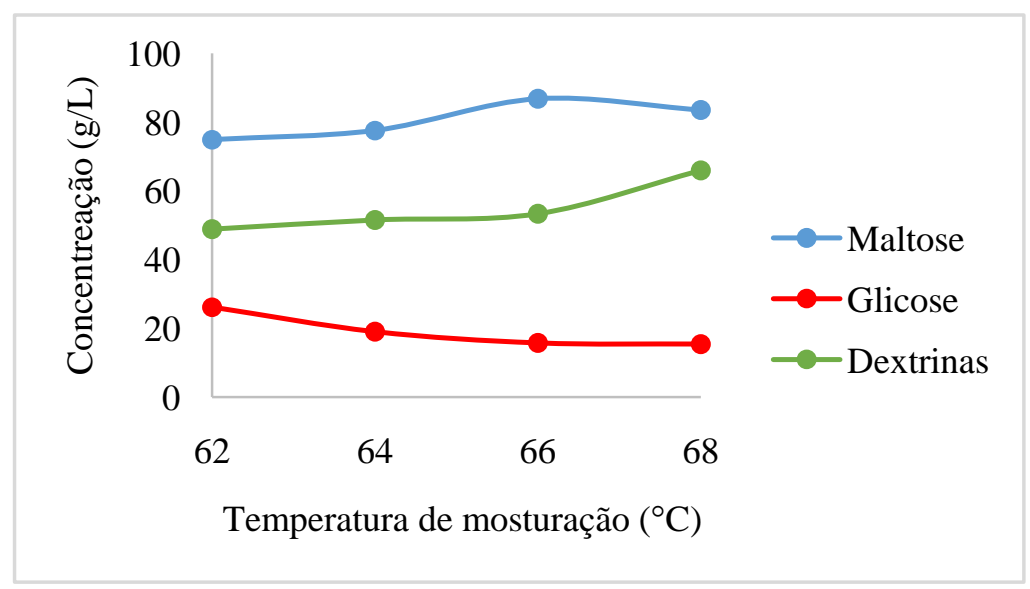

Figura 3 - Concentração de açúcares como função da temperatura de mosturação.

Desta forma, quando se busca produzir uma cerveja com predominância de açúcar residual, deve-se dar preferência à mosturação em temperaturas mais elevadas, em torno de $68^{\circ} \mathrm{C}$, pois os açúcares obtidos são de difícil conversão à álcool pelas leveduras. Por outro lado, cervejas com menor teor de açúcar residual deve ser mosturada em temperaturas mais brandas, de 62 a $66^{\circ} \mathrm{C}$, onde são obtidos açúcares fermentáveis. 


\section{CONCLUSÕES}

Diante aos resultados alcançados no presente trabalho, compreende-se que a temperatura de mosturação no processo de produção de cervejas tem grande influência nas características final da bebida. Isso se deve ao perfil de açúcares que são obtidos pela quebra enzimática do amido presente nos cereais. Na faixa estudada, em temperaturas mais baixas, há a predominância da atividade da enzima $\beta$-amilase, que produz açúcares de cadeias curtas, os quais são facilmente convertidos à álcool pelas leveduras. Por outro lado, nas temperaturas mais altas, o que se observa é uma maior ação da $\alpha$ amilase, que produz açúcares com cadeias longas, de difícil conversão à álcool.

\section{REFERENCIAS}

ARFELLI, G.; SARTINI, E. Characterisation of brewpub beer carbohydrates using high performance anion exchange chromatography coupled with pulsed amperometric detection. Food Chemistry, v. 142, n. 0, p. 152-158, 2014.

GEBREMARIAM, M. M.; ZARNKOW, M.; BECKER, T. Thermal stability of starch degrading enzymes of teff (Eragrostistef) malt during isothermal mashing. Process Biochemistry, v. 48, n. 12, p. 1928-1932, 2013.

GRASSI, S. et al. Beer fermentation: Monitoring of process parameters by FT-NIR and multivariate data analysis. Food Chemistry, v. 155, p. 279-286, 2014 a.

GRASSI, S. et al. Assessment of the sugars and ethanol development in beer fermentation with FTIR and multivariate curve resolution models. Food Research International, In Press, 2014 b.

LAMSAL, B. P.; WANG, H.; JOHNSON, L. A. Effect of corn preparation methods on dry-grind ethanol production by granular starch hydrolysis and partitioning of spent beer solids. Bioresource Technology, v. 102, n. 12, p. 6680-6686, 2011.

OREGLIA, Francisco. Enologia Teórico Prática. Buenos Aires: Instituto Solesiano de Arte Gráfica, 1979.

POMILIO, A. B. et al. Amino acid profiles and quantitative structure-property relationships for malts and beers. Food Research International, v. 43, n. 4, p. 965-971, 2010.

SILVA, F. et al. Electrophoretic and HPLC methods for comparative study of the protein fractions of malts, worts and beers produced from Scarlett and Prestige barley (Hordeumvulgare L.) varieties. Food Chemistry, v. 106, n. 2, p. 820-829, 2008. 